\title{
COVERED BRIDGES OF MADISON COUNTY
}

\author{
By Jon RoBison \\ Newspaper Division, Historical Building
}

Madison County, which considers itself "The Covered Bridge Capitol of the Midwest," claims seven of the twelve remaining covered bridges in Iowa. There are approximately 1,500 covered bridges still standing in the United States. However, nowhere in the Midwest can so many covered bridges be found grouped so closely together, for all Madison County's bridges are within an 11-mile radius of Winterset.

In the late 1880 's, Madison County had 16 covered bridges. Of the 16 bridges, those still standing are the Imes, Holliwell, Roseman, Hogback, McBride, Casper, and the Donahue. These bridges are still used for vehicular travel and are painted barn red. The nine dismantled bridges are the Cox, Cooper, Afton, Backbone, Rhyno, Rose, Brown, King and Klingensmith. When the bridges were first built, they were named after nearby land owners. The construction of the bridges differ in some respects; however, they were generally built on the lattice type of framing. The cost of construction ranged from $\$ 900$ to $\$ 1,900$, about twice the cost of constructing a roofless bridge. The bridges were made of wood, which was readily available, thus the canopies were necessary as unprotected wood tends to decay in 10 to 15 years.

When the historical society of Madison County was first organized in 1904, there were men living who could have given a complete list of the bridges, could have named the builders, the approximate cost of each bridge and who could have told many incidents relating to each covered bridge. Today there are differences of opinions as to the number and the size of the original bridges; there is agreement, however, to five of the bridges, the Cox, Cooper, Afton, Backbone and Rhyno, the Backbone being the only one of these still standing. 
There has been some conflict as to which bridge was built first. Here is a paragraph taken from a paper prepared by W. S. Wilkinson for a report for the County Board of Supervisors:

"The first bridge in the county was built in the fall and winter of 1854-1855 across Middle River where the Indianola and Winterset road crossed that stream in Scott township now known as the Holliwell bridge, two miles east of Winterset. Madison county paid John McCartney $\$ 500.00$ for building it. The bridge was a forty-foot span with framed approaches at each end. It was a frame bridge with double bents at each end of the spans twenty-two feet high. The timbers of this bridge were hewn sixteen inches square. The stringers of the main span were forty-four feet long to lap and the end of the bents. The framed approach at each end were twenty feet long. The bridge was finished early in the spring of 1855 ."

Other evidence, which supported the opinion that the Holliwell bridge was the first bridge to be built, was that it was through this bridge that the first mail route came. The bridge was washed away the night of the Centennial, and was rebuilt in 1880 .

The first Holliwell bridge was not a covered bridge; however, when rebuilt in 1880 , it was covered. It was built by $\mathrm{H}$. P. Jones and C. K. Foster. This is believed to be the longest of the covered bridges. Its structure is different from the other covered bridges in that it was of the covered wood bough truss type. The two center top beams are 39 feet long and arch from 9 to 13.2 feet above the floor. The two end top beams are 16 feet long and arch up to nine feet above the floor. The total length of the bough truss part is 110 feet and the approach spans 60 feet, the total length being 170 feet. The Holliwell bridge is at Sulgrove on North River in Douglas township; it was moved to replace a bridge which had fallen into the river. 


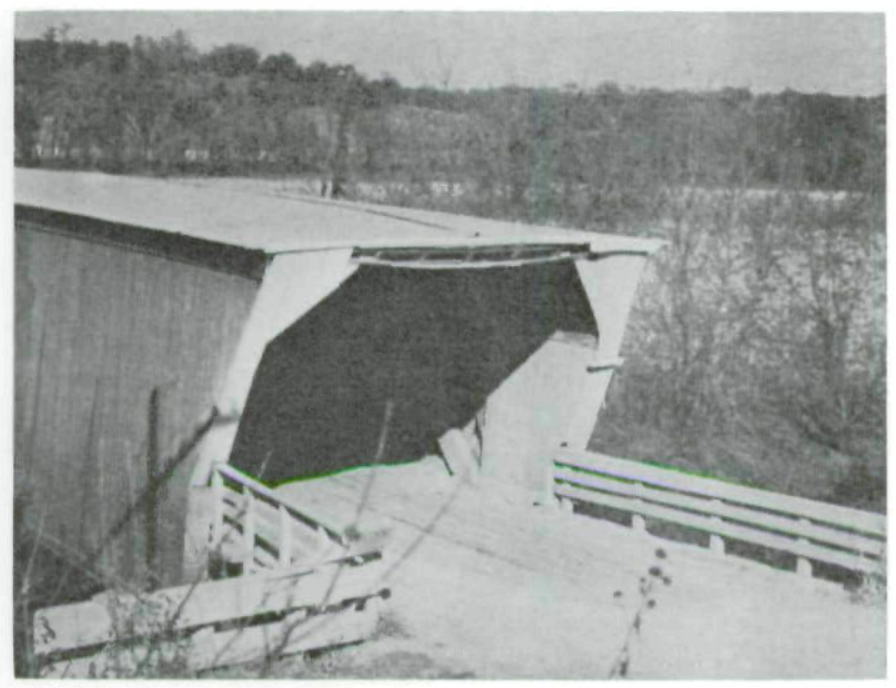

Courtesy of Winterset Madisonian

Holliwell Bridge

Alfred Cox believed that the first covered bridge was the one known as Cox bridge, which was built by his father, Eli Cox, in 1868 and remained standing until 1913, when the present bridge was built. The bridge, which was located over North River, was removed because it was thought that the piers were so placed as to obstruct the flow of the river. When the new bridge was built, the old piers were left standing.

The next bridge built was believed to have been the Brown bridge. It was built by J. P. Clark and there are reports concerning the the Wilkins, the Wiggins and the Donahue, saying that these bridges were built as soon as the cost of the Brown bridge had been paid. The Brown bridge was over the North River in the corner of Jefferson Township and was also called the Ballentine and in later years, the $\mathrm{W}$ a l ker or Fletcher bridge. It was at this bridge that, in 1896, Jim Donahue was shot by vigilantes who were guarding the bridge in an effort to recapture the jailbreaker Davies. Jim was only a lad; as he came riding to the bridge, the vigilantes ordered him to halt. Not realizing that he had been mistaken for the prisoner, he did not heed the order and was shot. 
At the January, 1870, meeting of the Board of Supervisors of Madison County, certain rules for building the county bridges were adopted. The Jan. 12, 1870, issue of the Madisonian had the following editorial:

\begin{abstract}
"Our Board of Supervisors have done well in adopting new rules to govern the erection of county bridges. There has been much complaint about the erection of county bridges and to the stability and make. The plan by the Board does away with the stone abutments thus saving such expense and enabling the county to build a number of more bridges. It is claimed that timber can be readily replaced and that ice will effect it less than stone. They also required that bridges shall be covered. The expense of the roof is more than made up by the permanency of the bridge. Instead of the old style framing for the support of the bent, they have adopted the lattice work frame like that used to support the ceiling of our courtroom."
\end{abstract}

The members of this board were E. Kincaid, William Anderson, R. P. Bruce, I. N. Hagle, H. H. Harris, E. H. Conger, V. B. Bissell, Otho Davis, J. M. Andrews and J. M. Croven. This was the last board having so many members in accordance with the law enacted in March, 1870. Only three supervisors were elected in the following October and they were the ones who determined the length of office of each by vote.

In 1870, the Board of Supervisors voted to construct a bridge at Wilkins Ford on Middle River. The bridge was to be built as soon as Brown bridge was paid for and there were sufficient funds. In October, the board received remonstrances against locating the bridge at Wilkins Mill. They asked for the location above the saw mill. The board took no action and the next mention of it was when W. H. Lewis was authorize to receive it in 1871. Nothing is said as to the builder. The bridge is in Section 36, Union township, and was afterwards known as Monger or Mills bridge. In September, 1877, it was ordered that this bridge be moved to Imes crossing of Clanton where it still stands and is now known as Imes bridge. This bridge is one of the two that has the original pitched roof. It is also sometimes called the King bridge. 


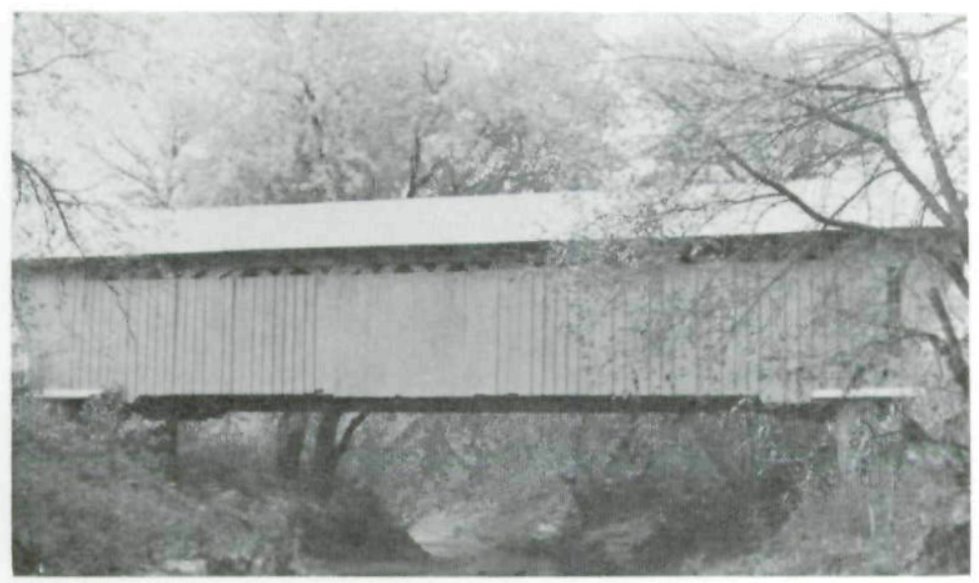

Courtesy of Winterset Madisonian

IMES BRIDGE

In June, 1870, the Wiggins bridge which is still standing was voted in the board. The bridge was located over the North river branch. The cost was not to exceed $\$ 1,700$, but later an additional $\$ 175$ was allotted for its completion. The Wiggins bridge is the one also known as the McBride or Burger bridge. The bridge was built by J. P. Clark. There is no evidence that the bridge described above is the one now located on this spot. The difference in construction of this bridge as compared to the Brown bridge, was due to the ruling of the board.

The construction of the Donahue bridge, which is still standing, was voted for in September, 1870. No records could be found as to the builder or the cost, but it is known that Eli Cox was the contractor. The bridge is on North River in Section 11, Crawford township, on the old Donahue road. It is the second of the two with the original pitched roof and it and the Burger have pins instead of iron bolts in what remains of the original structure. It is now called the Cutler bridge. 


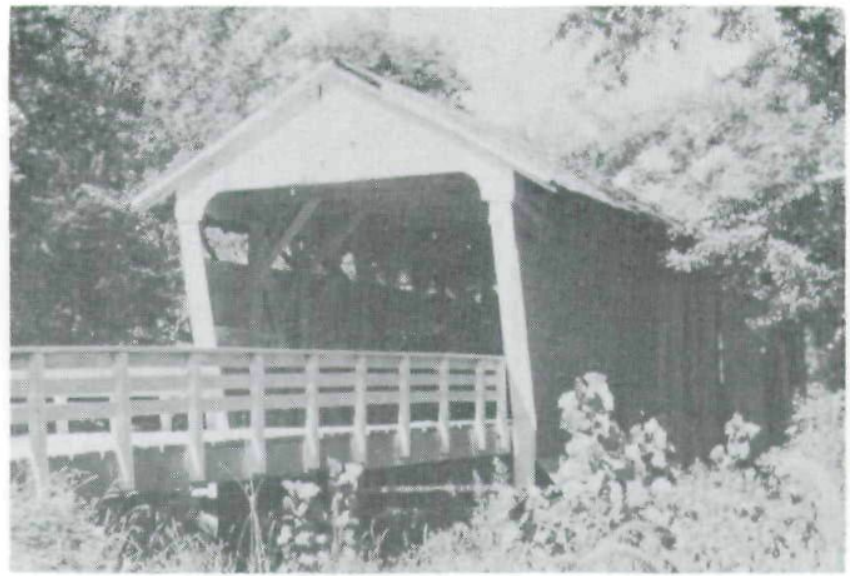

Pboto by Norma Brooks

Cutler Bridge

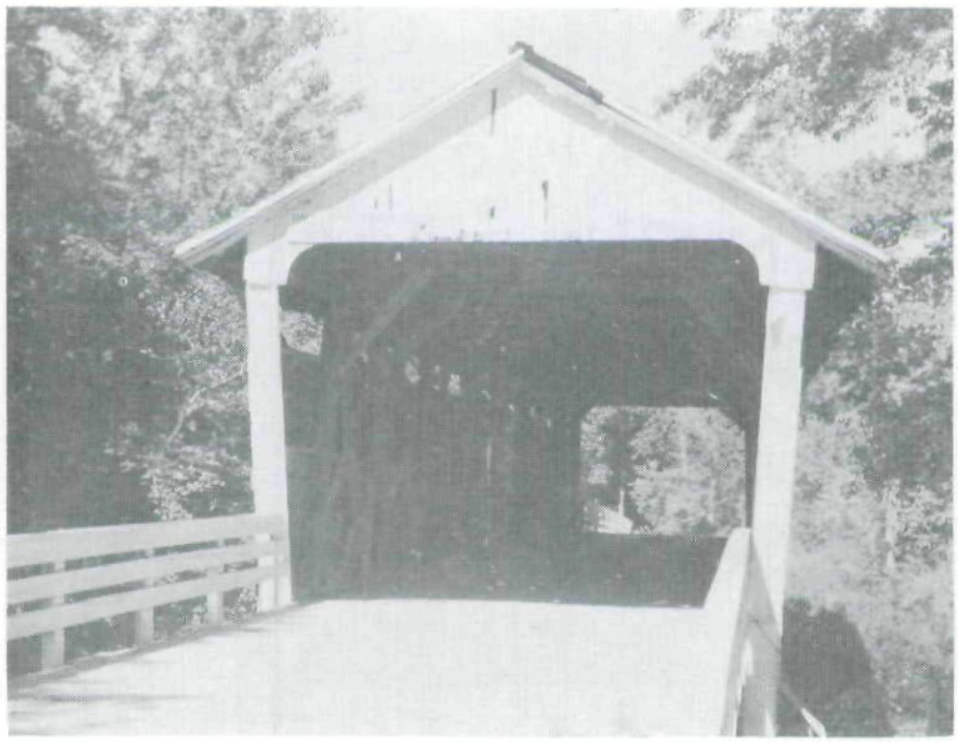

Photo by Joan Muyskens

Cutler Bridge 
The Afton bridge, which no longer stands, was ordered in June, 1871, the cost to be $\$ 1,800$ and the neighboring citizens to build thirty feet of apron. It stood east of where the old Afton road crosses the Middle River. The old road south from the Tusha school house was as it is today until it passed the horseshoe bend on the east side of the road. Here it turned on a narrow strip of high ground between the river and the horseshoe bend. A few hundred feet south it turned to the bridge it ascended, to the shelf on the side of the bridge, and it turned west to the present road. The bridge was taken out by ice in a spring flood about 1925. The road was then straightened and an iron bridge was built. This bridge fell into the river in the flood of 1947, and has since been replaced by a concrete bridge.

In August, 1871, the new bridge across North River in the Rose neighborhood in Jackson township was completed. This was considered a very superior bridge, being 45 feet long with approaches of 7 feet on one end and 30 feet on the other. The cost was $\$ 900$ and E. H. Conger was named to receive it.

An allowance was made for building the bridge at Rhynos Ford in April, 1872, and the contract was let to L. W. Winkley. The cost was $\$ 1,600$. This bridge was located on Clanton Creek in Section 2, South township. This was somewhat of a different site from the present bridge. Why this bridge was taken out is unknown.

In November, 1872, the first iron bridge in the county was built over Middle River at Comptons Mill. It was called the King iron bridge, manufactured at Iola, Kansas. Soon afterwards came iron bridges at Patterson and Bevington. The bridge at Bevington was agreed that Madison County pay $\$ 1,800$ on condition that Warren County would pay $\$ 50$ and that the petitioners would build the approaches. This marked the beginning of the end of the now historical covered bridges. 
In June, 1876, is the first mention of Cedar bridge on the De Soto road. Not until April, 1877, was it ordered. This bridge was moved to the next road crossing of Cedar when road number 16 or 169 was made. There was a new bridge built here. It is now called the Stors or Casper. This was a Jones bridge. At the time of its erection it was classified as the best bridge built.

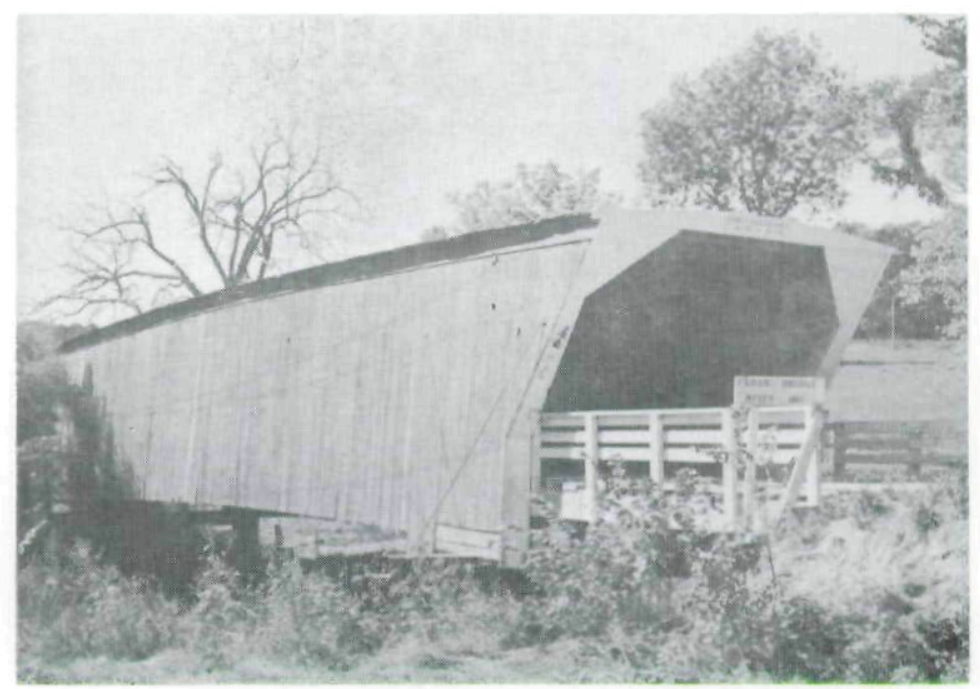

Pboto by Norma Brooks

Cedar Bridge

The Roseman bridge was also voted on in April, 1877, and let to Mr. Jones who evidently waited until 1883 to build the bridge, after which he built the Cedar bridge. The Roseman bridge was located in Section 14 and is still standing just north of the Old Oak Grove Church. Mr. Jones had trouble on the Roseman bridge but from it he did a better job on the Cedar bridge. The Roseman bridge was 113 feet long and said to be substantial enough to last a century. This bridge was sometimes called the "haunted bridge" but the origin of the name could not be found. 
The next bridge constructed was the King, McMellan or Welch bridge voted in 1877. It was located over Badger Creek in Section 20, Lee township. It was to be built under the supervision of Milton Wilson. In June, 1878, J. P. Clark received final payment for the building of the bridge. This bridge was the smallest of the covered bridges and later proved too narrow for passage of larger vehicles. Timbers were removed from time to time and the bridge was gone by the late 1920 's.

In June, 1877, an appropriation was made for a bridge at Coopers Ford in Douglas township. This must have been the second bridge at this place, for the records of 1886 specified that a bridge be built at Cottonwood Ford on North Branch, similar to the one at Coopers Ford. This bridge was probably built in 1878 and the contractor was Eli Cox. It was washed out in the spring flood of 1898. It was then moved a quarter mile east of that road. The road was straightened to run due north and south on the township line establishing the "Hilderbrand" road. When Hwy. 169 was located, the road was moved to the west again.

The early history of the Backbone bridge is lacking and may belong to a period of which no records were found. The first mention of it was in 1878. At this time W. H. Lewis was authorized to have the bridge repaired. The first site was near the end of the tunnel. It was the victim of the flood of 1876. In August, 1878, it was ordered to be torn down and rebuilt where the road crosses Middle River. Some men say that it was not a covered bridge at first but eventually was covered. On July 8, 1914, it burned. It served other purposes such as a barn for storing hay and grain and as a convenient place for holding political meetings. The present bridge is located in the Pammel State Park.

The Hogback bridge was built in 1884. This was also a Jones bridge. No records were found on this bridge. 


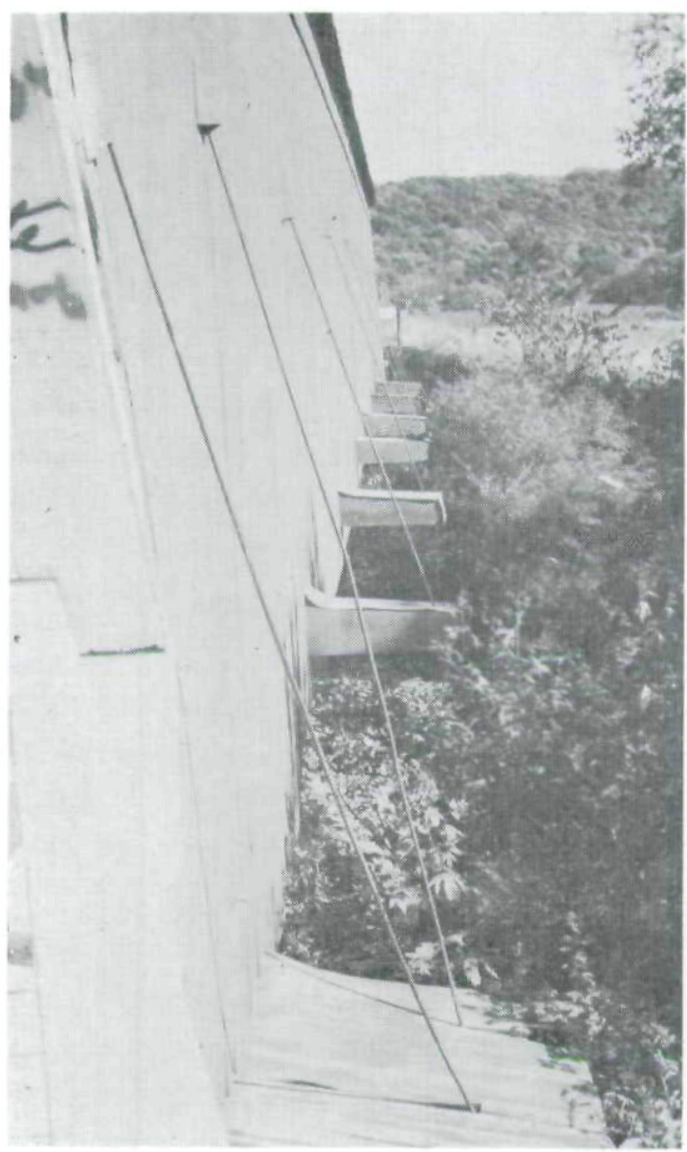

Photo by Joan Muyskens

Side View of Hogback Bridge Showing THE Exterior Bridge Supports

The Klingensmith bridge on North branch in Section 23, Madison township, was removed not long after 1933. H. P. Jones was said to have been the builder. 


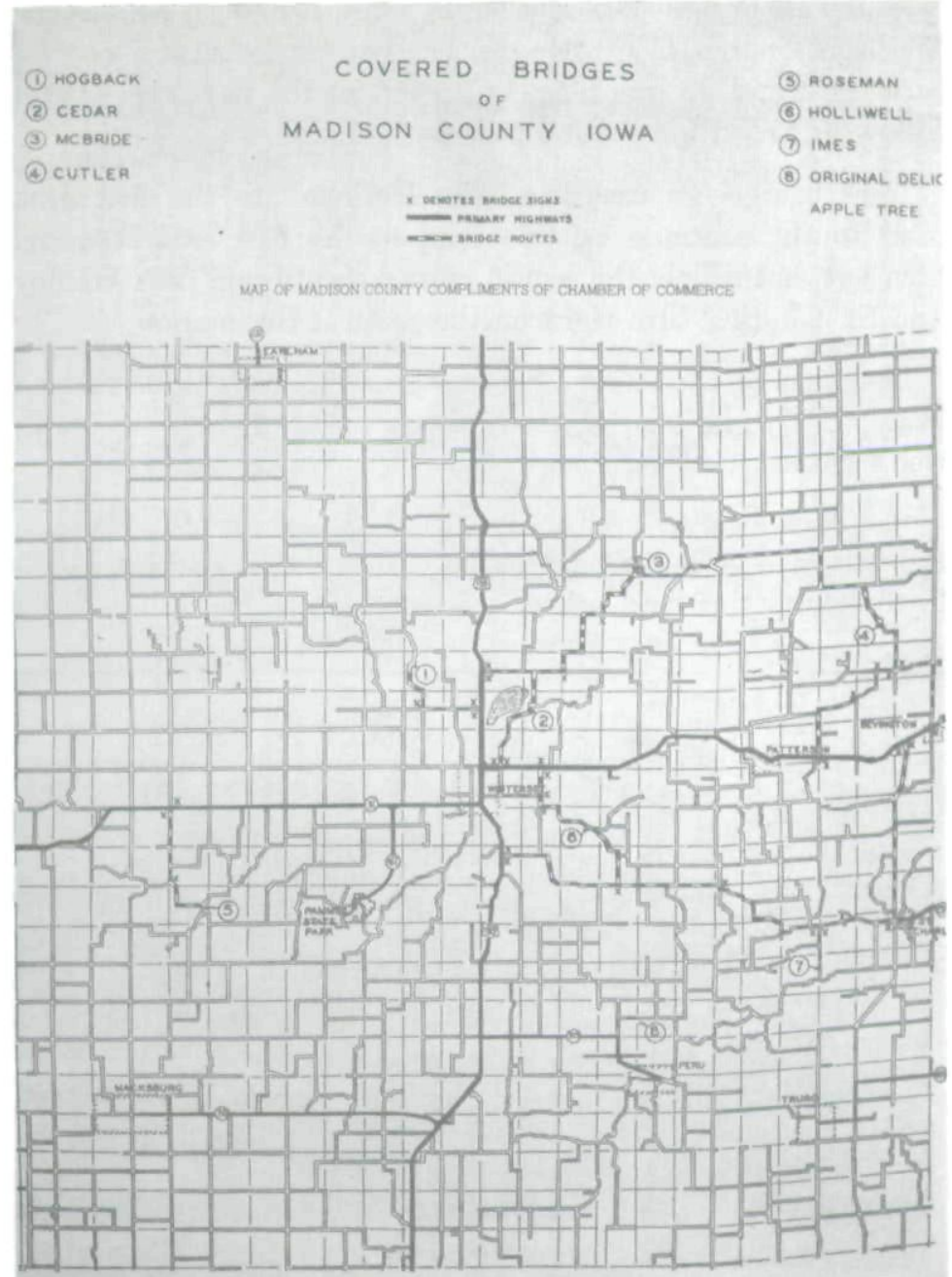

RDGE SIGNS COMPLIMENTS AMEAICAN LEGION GREEN ROGERS POST IBA

WINTERSET IOWA

Courtesy of Madison County Chamber of Commerce

Map Showing Location of Bridges

A more accurate description for finding the seven remaining bridges in Madison County is as follows: 
Holliwell bridge-take the street along the south side of the Madison County Court House, go east to the first T-corner, turn right and go one block; turn left at the next corner and follow this road for about a mile and a half.

Imes bridge-go east from the Holliwell to the first rock road south; continue on this road to the first east crossing, turn left and follow the legion markers until you pass Hanley and St. Charles, turn right on the road at the marker.

Roseman or Oak Grove bridge-go west from Winterset on Hwy. 92 for eight miles, turn left on the rock road and go to the Y-corner, turn right and follow this road to the bridge.

Hogback bridge-take Hwy. 169 north from Winterset to the first road going left; take this road to the second rock road to the right, turn and follow this road to the bridge.

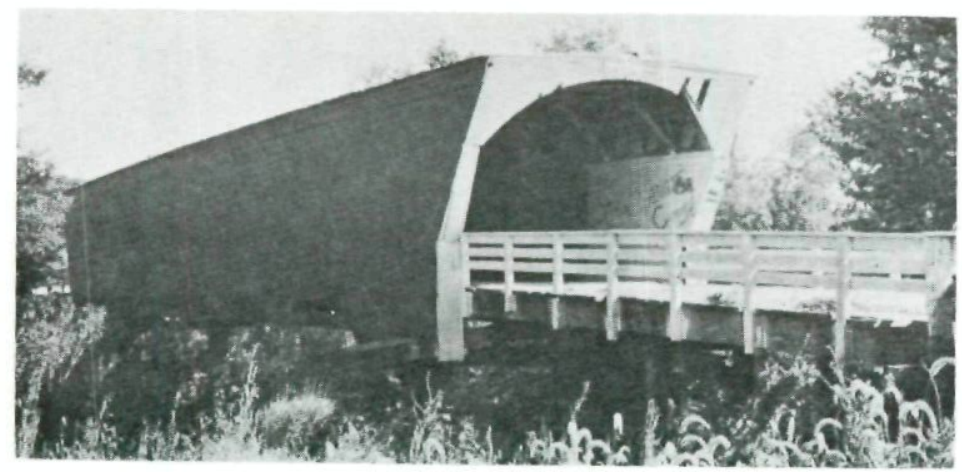

Pboto by Norma Brooks

Hogback Bridge

Cedar or Casper bridge-take Hwy. 92 west from Winterset about half a mile to the first turn to the left; turn on this road and follow it about three miles to the bridge. 
Donahue or Cutler bridge-take Hwy. 92 east from Winterset to the main street of Bevington; turn north to the first road to the left, follow this road to the first Y-corner, turn right and continue about one mile.

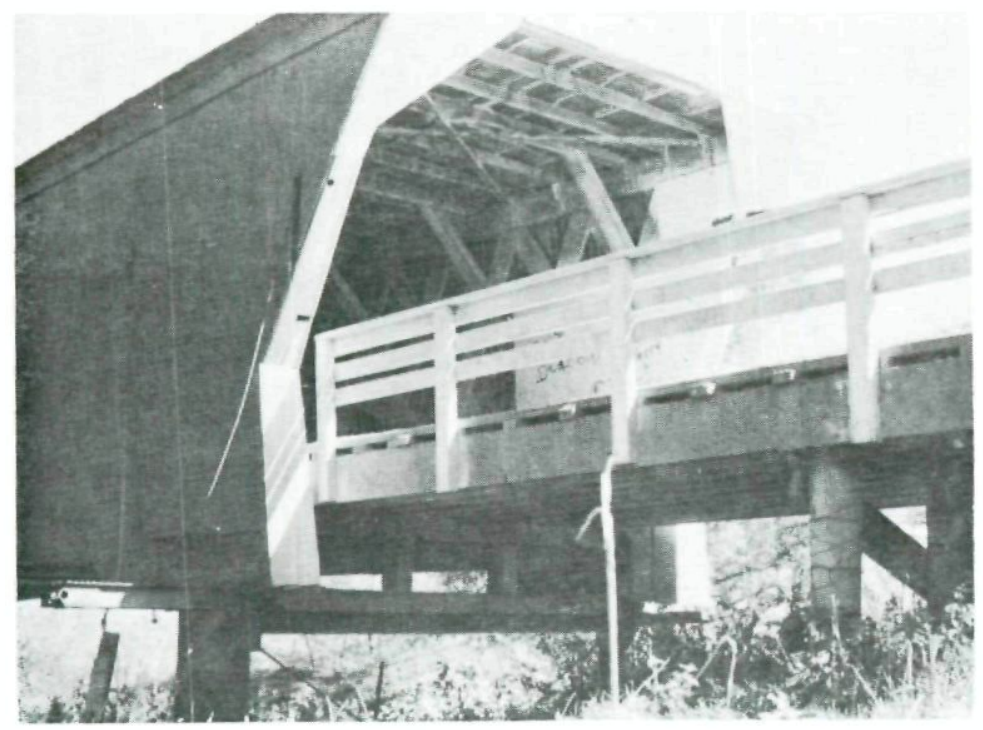

Pboto by Joan Muyskens

View of Cedar Bridge Showing Ground Supports

McBride bridge-go through the Cedar bridge and continue to the first T-road, turn right and take this road to the first road going left; take this road, angle left at the first fork, as marked; continue to second fork, angle left again and continue to bridge, also marked. 


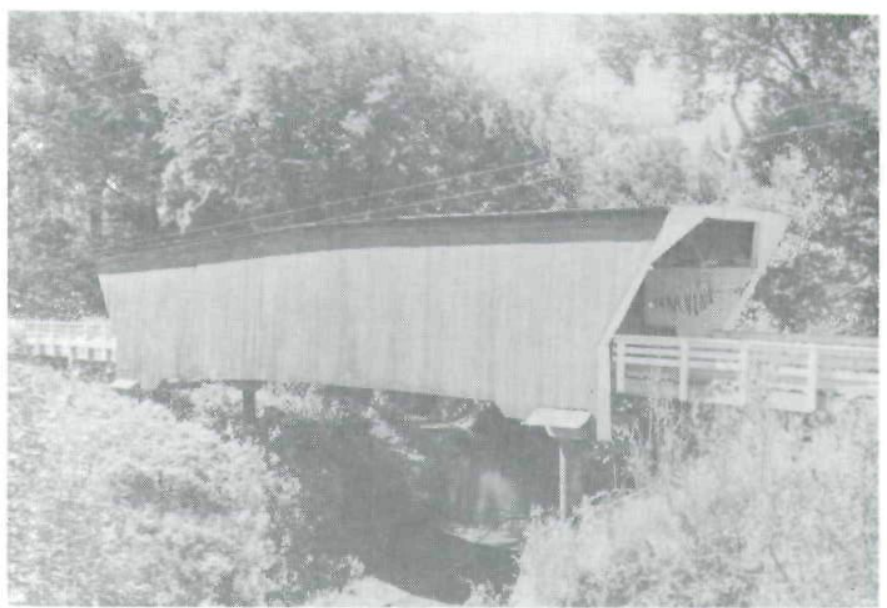

Photo by Norma Brooks

MCBrIDE BrIDGE

References: The Winterset Madisonian; Mrs. Fred Hartsook, Spencer, Iowa; Wallace's Farmer, July, 1966; History of Madison County, Vol. I; Madison County Historical Society; various newspaper articles, Iowa State Historical Building.

\section{PANORAMA . .}

Panorama will be discontinued because of lack of response. However, if we can be of any help to you concerning Iowa history, feel free to write us.

\section{CORRECTIONS . . .}

The last issue published, Summer, 1966, was Vol. XXXVIII (38), No. 5, not Vol. XXXVII (37), No. 5, as printed on the cover.

Page 362, Summer, 1966: the first two italic lines in the "Letters" should have been placed under the line reading "In studying Iowa History ...." 
Copyright of Annals of Iowa is the property of State of Iowa, by \& through the State Historical Society of Iowa and its content may not be copied or emailed to multiple sites or posted to a listserv without the copyright holder's express written permission. However, users may print, download, or email articles for individual use. 